\title{
O TRÁGICO, O CÔMICO E A "DISTÂNCIA ARTÍSTICA”: ARTE E CONHECIMENTO N'A GAIA CIÊNCIA, DE NIETZSCHE
}

\author{
Ernani Chaves ${ }^{l}$ \\ ernanic@amazon.com.br
}

A Jeanne-Marie Gagnebin, cada vez mais próxima, na distância.

RESUMO A partir da leitura de A Gaia Ciência, pretendemos mostrar alguns elementos importantes que, nesse livro, se constituem em torno do tema da "distância". Analisando principalmente três aforismos do livro, procurase esclarecer o deslocamento no texto e no pensamento de Nietzsche da distância como Ferne, de origem romântica, à distância como Distanz. Entretanto, procura-se ao final mostrar que Nietzsche desloca o tema romântico da Ferne, caracterizando-a como uma "distância artística", que se torna o traço distintivo entre a perspectiva da arte e a perspectiva do conhecimento.

Palavras-Chave Distância, Trágico, Cômico, Arte, Conhecimento

ABSTRACT This reading of The Gay Science intends to show some important elements which, in this book, gravitate around the theme of "distance". Analysing particularly three aphorisms of the book, our goal is to clarify the movement, in the text and in Nietzsche's thought as well, from distance as Ferne, with its romantic source, to distance as Distanz. However,

1 Professor do Departamento de Filosofia da Universidade Federal do Pará. Artigo recebido em 15/09/05 e aprovado em 15/11/05.

KRITERION, Belo Horizonte, nº 112, Dez/2005, p. 273-282 
in the end, we intend to show that Nietzsche dislocates the romantic theme of the Ferne, taking it as an "artistic distance", which becomes the distinctive trace between the perspectives of art and knowledge.

Keywords Distance, Tragic, Comic, Art, Knowledgement

As chamadas obras do "segundo período" do pensamento de Nietzsche, em que se incluem, canonicamente, as duas partes de Humano, demasiado humano, Aurora e A gaia ciência, escritas e publicadas entre 1877 e 1882, têm merecido muito pouca atenção por parte dos estudiosos brasileiros. ${ }^{2}$ Isso se deve muito a uma espécie de anátema que recaiu sobre elas, como se elas fossem a expressão do positivismo de Nietzsche ou ainda mero momento de transição entre os escritos fulgurantes da "juventude" e as "grandes obras" da "maturidade". Aquele que resolver fazer uma pesquisa, consultando, por exemplo, livros, revistas, jornais ou ainda o Banco de Teses da Capes, poderá constatar que a grande maioria de estudos sobre Nietzsche (e são muitos, demasiado até!) acaba girando em torno de três textos-fetiche: $O$ nascimento da tragédia, Assim falou Zaratustra e Genealogia da Moral. Mais ainda: delegam aos chamados conceitos fundamentais forjados no "terceiro período", em especial os de eterno retorno, além-do-homem e vontade de potência, o papel de conceitos-chave, definidores em última instância, do pensamento de Nietzsche (e aqui seguem Heidegger, explícita ou implicitamente). O fato de Nietzsche ter retomado, nos seus textos finais, inúmeros temas e motivos de seu primeiro livro facilita a conexão entre a primeira e a terceira fases, ficando, assim, a segunda relegada sempre a um papel secundário. Acrescentaria, enfim, mais um motivo para o relativo esquecimento desses textos: eles não permitiram uma apropriação imediata e rápida pelos chamados teóricos da pósmodernidade, assim como caucionam muito pouco também a idéia de um "pensamento fraco".

Meu objetivo, nos últimos tempos, tem sido justamente o contrário. Tenho procurado mostrar o quanto os livros da chamada segunda fase, todos eles "livros de aforismos", o que marca a sua singularidade, contêm elementos extremamente indispensáveis e importantes, sem os quais as grandes obras da

2 A exceção nesta periodização é o Livro V de A Gaia Ciência, escrito e publicado em 1886, ou seja, em plena vigência do que se convencionou chamar de "terceira fase". 
maturidade permanecem, de certo modo, incompreensíveis. Além disso, seguindo a proposição de Mazzino Montinari, ${ }^{3}$ considero que a ruptura maior no pensamento de Nietzsche acontece já com Humano, demasiado humano. Seu desligamento de Wagner é aqui fundamental, na medida em que torna possível uma avaliação da arte enquanto tal e não mais, como anteriormente e desde $O$ nascimento da tragédia, circunscrita à arte moderna. Nietzsche conserva certamente a centralidade dos "impulsos artísticos", mas em relação a eles promove um duplo deslocamento: em primeiro lugar, revela seus contornos históricos, porta de entrada para a compreensão do passado, em que arte e religião, juntas, formam um dos elos decisivos; em segundo lugar, critica a arte suprema de seu tempo, a de Wagner, denunciando-a, desde aí, como o ponto culminante do histrionismo e da atitude aversiva em relação à ciência. A esta imagem do Dichter, do poeta, como o "criador" por excelência, Nietzsche opõe a do frei Geist, o espírito livre. Enquanto no período do Nascimento da tragédia o mundo necessitava ainda de uma "justificação estética", agora é justamente a "faculdade estética" que distancia a humanidade cada vez mais da verdade. A "necessidade metafísica", que antes era ainda um "consolo", não é mais uma necessidade eterna, mas, ao contrário, profundamente histórica, de tal modo que nos restaria apenas a busca por uma sabedoria contemplativa ideal, que Nietzsche forjou, justamente, através da imagem do "espírito livre".

Esse processo de livramento das ilusões juvenis se completa em Aurora pela concepção de uma neue Leidenschaft, uma passio nova, tal como aparece nos fragmentos preparatórios ao livro, e recebe sua formulação mais acabada no aforismo 429, intitulado "A nova paixão". Nosso medo de retornar à barbárie, nosso ódio à barbárie - assim começa Nietzsche o aforismo ${ }^{4}$ — deve-se ao fato de que nossa felicidade é impensável sem a "pulsão para o conhecimento", daí ser impossível para nós pensar a felicidade sem o conhecimento. Nesta perspectiva, retomando o De l'amour, de Stendhal, Nietzsche considera a "paixão do conhecimento", essa "nova paixão", como a mais extremada de todas as paixões, caracterizando-a com os mesmos termos atribuídos, tradicionalmente, à paixão amorosa: a "intranqüilidade" provocada por essa "nova paixão" é semelhante àquela provocada no amante por um "amor infeliz",

3 Ver por exemplo, de Montinari, Nietzsche lesen, Berlin/New York: de Gruyter, 1982, e Friedrich Nietzsche. Eine Einführung. Berlin/New York: de Gruyter, 1991.

4 Todas as citações a Nietzsche seguem a edição Colli-Montinari: Kritische Studienausgabe (KSA), Berlin/ New York/München: de Gruyter, 1982. As obras do segundo período, à exceção da segunda parte de Humano, demasiado humano, foram publicadas pela Companhia das Letras, na tradução de Paulo César Souza, a quem sempre recorremos, assim como à de Rubens Rodrigues Torres Filho, na coletânea organizada por Gerard Lebrun para a Coleção "Os Pensadores". 
não correspondido. ${ }^{5}$ Entretanto, tal como o apaixonado infeliz, o apaixonado pelo conhecimento prefere os tremores e sustos da intranqüilidade à indiferença aparentemente apaziguadora. Em outras palavras: a paixão não teme a dor e não renuncia a ela em nome de um estado não-doloroso. Nessa perspectiva, a paixão do conhecimento não é apenas um amor apaixonado, mas também um amor infeliz:

\begin{abstract}
A inquietude de descobrir e de solucionar tornou-se tão atraente e imprescindível para nós como o amor infeliz para aquele que ama: o qual ele não trocaria jamais pelo estado de indiferença; — sim, talvez nós também sejamos amantes infelizes! O conhecimento em nós transformou-se em paixão que não vacila ante nenhum sacrifício e nada teme, no fundo, senão sua própria extinção; nós acreditamos honestamente que, sob o ímpeto e o sofrimento dessa paixão toda a humanidade tenha de acreditarse mais sublime e consolada do que antes, quando ainda não havia superado a inveja do bem-estar grosseiro que acompanha a barbárie. ${ }^{6}$
\end{abstract}

Com toda a sua dor, essa nova paixão, sempre pronta a se sacrificar por "toda a humanidade", pode representar tanto uma nova elevação quanto uma nova consolação. Uma nova elevação, na medida em que nos distancia da barbárie e de seu prazer grosseiro: a paixão do conhecimento engendra o "sentimento de poder". ${ }^{7}$ Uma nova consolação, pois se as verdades, unicamente por seu conteúdo, não consolam, a paixão do conhecimento, entretanto, pode ainda consolar-nos, pois a intranqüilidade do descobrir e do tatear não depende, tal como a alegria na caça, da natureza das verdades encontradas. Mas essa nova elevação e esse novo consolo não podem nos desviar do "grande paradoxo" da paixão, qual seja, o de que também por causa dela, a humanidade inteira pode perecer, pois a "paixão pelo conhecimento" engendra também o "Don Juan do conhecimento". ${ }^{8}$ Não por acaso, "a alegria na caça" retoma a caracterização do "amor à la don Juan" em Stendhal como "um sentimento no gênero do gosto pela caça", como uma crescente necessidade "que deve ser despertada por objetos diversos" e que coloca "sem cessar" em dúvida, o talento do conquistador. ${ }^{9}$ Comparando "Don Juan" ao "Werther", de Goethe, Stendhal acentua no primeiro a relação entre a infelicidade da inconstância e o tédio, entre a infelicidade, o desespero e a morte; enquanto ao segundo ainda encanta, por mais fugaz que seja, a visão da mulher amada, a descoberta da novidade, a

5 Desenvolvi as relações entre Nietzche e Stendhal em meu texto " $L$ 'amour, la passion: Nietzsche e Stendhal", In: AZEREDO, Vânia Dutra de (Org.). Falando de Nietzsche. ljuí: Unijuí, 2005. p. 41-54.

6 Aurora, aforismo 429.

7 Aurora, aforismo 146.

8 Aurora, aforismo 327.

9 De l'amour, Édition de V. Del Litto. Paris: Gallimard, 1990. Cap. LIX, p. 241. 
atividade em oposição ao tédio. A "paixão do conhecimento" para Nietzsche reúne esse paradoxo, tornando-se uma mistura entre o amor-paixão segundo Don Juan e Werther, em que a descoberta feliz do novo e a possibilidade de perecimento caminham juntas. ${ }^{10}$

Em A Gaia Ciência, a paixão pelo conhecimento vai ser pensada, entre outros, por meio do tema do "afastamento", da "distância", do "longe", que Nietzsche grafa ora como Ferne, ora como Distanz, numa oscilação terminológica que não deve nos escapar. O fio condutor desse tema nos é dado pelo aforismo 15 do livro intitulado, significativamente, Aus der Ferne: "De longe", como quer a tradução de Paulo César Souza. A ressonância romântica do tema ${ }^{11}$ é evidente desde o começo do aforismo e sua referência à montanha que domina inteiramente a paisagem, transmitindo um forte estímulo não apenas para o espectador, mas também para a própria paisagem. Ora, diante dessa imponência natural e sua atração, o impulso em escalar, em subir até o seu cume é inevitável. Aqui reencontramos um tema central da estética romântica (em conjunção com a filosofia da natureza, desde Schelling e Goethe) em especial da pintura, que deve ser, antes de tudo, uma "pintura de paisagens", uma Landschaftsmalerei, que se caracterizará, nos rastros da Terceira Crítica de Kant, como uma "pintura do sublime". ${ }^{12}$ A natureza tem o papel de elevar a imaginação e de torná-la sensível à experiência do sublime, e, para o romantismo de Jena, essa idéia significa que a natureza não é apenas uma representação negativa do sublime, mas, ao contrário, o sublime está na natureza - a natureza transforma-se em uma espécie de "teofania" —,${ }^{13}$ e a mediação da arte tornará possível sua apreensão pela via do conhecimento teórico. Com isso, a pintura romântica pôde colocar em primeiro plano a paisagem e não mais as pinturas religiosas ou históricas, como até então era comum. A obra artística de Caspar David Friedrich, imersa em uma luz crepuscular, constitui-se, talvez, no corolário dessa perspectiva, em que o "olho espiritual" e não o "olho do corpo" dialoga com o mundo exterior, como em um processo mediúnico. ${ }^{14}$

10 Cf. a respeito, BRUSOTTI, Marco. Die Leidenschaft der Erkenntnis. Philosophie und ästhetische ebensgestaltung bei Nietzsche von Morgenröthe bis Also sprach Zarathustra, Berlin/New York: de Gruyter, 1997; e MONTINARI, Mazzino. Nietzsches Philosophie als "Leidenschaft des Erkenntnis". In: Nietzsche lessen. Berlin: Walter de Gruyter, 1982, p. 64 et seq.

11 Acerca da complexa relação entre Nietzsche e o romantismo, que não será o objeto deste artigo, cf. BEHLER, Ernst. "Nietzsche und die frühromantische Schule". In: Nietzsche Studien, v. 7, Berlin, Walter de Gruyter, 1978.

12 Cf. a respeito ANDRADE, Ricardo Sobral de. A face noturna do pensamento freudiano. Freud e o romantismo alemão. Niterói: Editora da UFF, 2000, p. 112 et seq.; LOUREIRO, Inês. O carvalho e o pinheiro. Freud e o estilo romântico. São Paulo: Escuta/Fapesp, 2002, p. 226 et seq., assim como os textos organizados por Jacob Guinsburg na coletânea O Romantismo (3. ed. São Paulo: Perspectiva, 1993). Lembremos ainda a preferência de Kant pela pintura, tal como o diz claramente o parágrafo 52 da Terceira Crítica.

13 Cf. NUNES, Benedito. A Visão Romântica. In: GIUNSBURG, J. (Org.). O Romantismo, p. 64.

14 Cf. ZANINI, Walter. A arte romântica. In: GIUNSBURG, J. (Org.). O Romantismo, p. 203. 
Ora, se o ponto de partida do aforismo de Nietzsche é romântico, seu ponto de chegada, ao contrário, não o é. Isso talvez explique a passagem terminológica da Ferne do título a Distanz no interior do aforismo. Por que essa mudança? Porque a Ferne romântica, que impulsiona o espectador à tentativa de apreender o sublime na natureza, revela-se, ao final, absolutamente ineficiente e frustrante, pois induz ao esquecimento da Distanz, ou seja, ao esquecimento de que "algumas grandezas, como algumas bondades", só podem ser vistas "a uma certa distância, Distanz". E mais ainda: a uma distância não de cima, mas de baixo! Nietzsche está aqui em total contraposição à mais famosa das pinturas de Caspar David Friedrich, intitulada Der Wanderer über den Nebelmeer, de 1818, na qual o "andarilho", de costas para o espectador, vestido à moda burguesa, contempla do alto de uma montanha a névoa, que, misturada como um mar revolto, se estende à sua frente. Dessa perspectiva, Distanz tem, no vocabulário nietzscheano, o sentido crítico de se opor à ilusão romântica, alimentada pelo topos da Ferne. Esse traço crítico é retomado ao final do aforismo, quando, dirigindo-se a um interlocutor, a um leitor imaginário, Nietzsche afirma que alguns homens "próximos de ti", in der Nähe, precisam rever sua própria idéia de "autoconhecimento", se ainda se alimentam dessa ilusão, ou seja, se ainda "necessitam se ver apenas a partir de alguma distância, Ferne", para que possam se achar suportáveis, atraentes ou admirados. A "arte de viver", na qual Nietzsche está empenhado neste momento, não pode, portanto, ser conduzida pela possibilidade do conhecimento do sublime expresso na natureza. A distância como Ferne acaba se tornando, aos olhos de Nietzsche, uma espécie de nostalgia imobilizadora, que acredita ainda que o mundo tem um sentido a ser encontrado, que uma vez descoberto implica, na mesma medida, na descoberta de si mesmo.

O mesmo princípio argumentativo preside a formulação do aforismo 60, "As mulheres e seu efeito a distância". Se a palavra que abre o aforismo já no seu título é Ferne, a sua última palavra é justamente Distanz. E o que se passa entre uma e outra, isto é, do que se trata nesse aforismo? Se, no aforismo anteriormente comentado, tudo girava em torno do ver e da possibilidade de apreender o visto pelo intelecto, aqui se trata de enfatizar o ouvir e, de certa forma, da "regressão da audição" no mundo moderno. Ora, o mundo moderno penetra no sujeito através do ouvido, é por ele que o barulho, incluindo mesmo uma ária, "ensurdece como um touro mugindo", ${ }^{15}$ transformando a vida em um "labirinto infernal". Eis então que surge, não de muito longe, um grande veleiro, "silencioso como um fantasma" (em uma provável referência ao "Navio 
fantasma" wagneriano), uma "beleza fantasmagórica", "enfeitiçadora", "espectral". Como se esse navio carregasse consigo toda a tranqüilidade e o silêncio do mundo, como se, enfim, a felicidade encontrasse seu lugar no silêncio, como se o "eu (Ich) feliz", o "meu segundo si mesmo (Selbst) eterno" encontrasse a paz não estando nem vivo, nem morto.

O romantismo é criticado aqui juntamente com o niilismo schopenhauriano, em que a idéia de felicidade está acoplada a esse estado de Nirvana, de indiferença à dor e ao prazer, esse não estar nem morto nem vivo, como diz Nietzsche. Ou ainda, lembrando "O navio fantasma", a história do "holandês errante", tal como contada por Wagner, que como Odisseu ou o "judeu errante" encarna a nostalgia do repouso, da tranquiilidade após a longa e cansativa viagem. Por isso, esse veleiro se compara, com suas "brancas velas", a uma "imensa borboleta" (novamente a idéia de "sublime") correndo "sobre o mar escuro", ou seja, "correndo sobre a existência", na medida em que ignora que a existência é um composto de dor e prazer. Todo esse ruído, nos diz Nietzsche, conduz-nos a acreditar, que a felicidade está na quietude e na distância, na Ferne. Novamente, a distância compreendida como Ferne pertence ao vocabulário romântico e à visão de mundo romântica, que Nietzsche continua a criticar, pois ela supõe uma nostalgia que vira as costas à existência, à afirmação da vida na sua integridade, para idealizar um Nirvana, um mundo em que não se é nem vivo, nem morto, onde o errante deseja um porto feliz, um ancoradouro seguro. Ora, por isso não podemos nos enganar com a promessa de felicidade, enquanto quietude e repouso, encarnada pela fascinação feminina, como se à proximidade das mulheres, ao seu lado enfim, pudéssemos encontrar a felicidade e a reclusão. E aqui, antecipando as célebres páginas iniciais de Além de Bem e Mal, em que Nietzsche constrói uma espécie de fábula, na qual a "verdade-mulher" escapa freqüentemente do caçador-filósofo, ele se refere à "fascinação e ao poderoso efeito das mulheres" segundo a linguagem dos filósofos, isto é, a linguagem da metafísica, como um "efeito na distância", eine Wirkung in die Ferne. Mas para acrescentar, logo em seguida, primeiro em latim, um actio in distans e enfim completar: "o quer requer antes e acima de tudo - distância, (Distanz)!". O círculo se fecha: o efeito à distância das mulheres, quando expresso na linguagem da metafísica, encontra-se no mesmo diapasão da perspectiva romântica, na medida em que a mulher seria a encarnação idealizada da felicidade, de onde decorrem sua fascinação e seu poder. Entretanto, tal idealização só faz acentuar, ao contrário, seu parentesco com a destruição e a morte, tal como "Senta", a mulher por quem o "holandês errante" wagneriano se apaixona. Ao exigir mais uma vez a Distanz, ao invés da Ferne, é como se Nietzsche, na contramão dos movimentos feministas de 
sua época e que ele tanto criticou, insistisse na historicidade do "feminino", para além das idealizações da mulher, tão próprias ao romantismo e aos movimentos reivindicatórios.

Por fim, no aforismo 107, "Nossa última gratidão para com a arte" (na tradução de Rubens Rodrigues Torres Filho), Nietzsche introduz o tema da künstlerische Ferne, da "distância artística", não fazendo nenhuma referência à Distanz. O que isso significa? Que Nietzsche sucumbe ao romantismo? Ou que ele transforma a Ferne romântica em outra coisa?

Lido atentamente, esse aforismo nos mostra que a questão de uma "arte de viver", Lebenskunst, que Nietzsche desenvolve n'A Gaia Ciência, retoma o tema da vida como fenômeno estético, que já aparece n'O nascimento da tragédia. Ora, o que separa esses dois livros, o que distingue neles a compreensão da vida como fenômeno estético é justamente o tema da "distância", ausente no primeiro livro. Mais ainda, uma "distância artística" e não uma distância qualquer. Eis aqui, parece-me, a subversão que Nietzsche faz no tema romântico da Ferne, ou seja, acrescenta-lhe uma dimensão propriamente "artística", o que é possível de ser expresso tanto através do trágico, quanto do cômico. Eis, portanto, "nossa última gratidão para com a arte": se a existência ainda nos é suportável pela arte, se por meio dela "nos são dados olhos e mãos e, sobretudo, boa consciência", ${ }^{16}$ então nossa tarefa é poder fazer de nós mesmos um fenômeno estético, fazer de nossa vida uma obra de arte. Nietzsche relativiza, dessa maneira, sua contundente crítica à relação romântica entre o "longe" e o "autoconhecimento", tal como o enunciava o aforismo 15. Ele diz agora que "ocasionalmente precisamos descansar de nós mesmos, olhando-nos de cima e de longe", mas imediatamente acrescentando: "e, de uma distância artística, rindo de nós ou chorando por nós". Dessa perspectiva, ao contrário de $O$ nascimento da tragédia, uma "perspectiva a partir da distância" é essencial ao trágico e ao cômico. Assim sendo, a consideração da distância não marca a diferença entre o trágico e o cômico, mas sim a diferença entre a perspectiva da arte e a perspectiva do conhecimento. Estamos, como se vê, bem longe do positivismo! No trágico, distanciar-se de si significa transfigurar-se e elevar-se; no cômico, ao contrário, significa ganhar distância de si através do humor. A perspectiva da arte distingue-se da do conhecimento justamente porque prescinde da "distância artística", o que desemboca em uma única certeza possível: a de que em nossa paixão pelo conhecimento há sempre algo de herói e de tolo. "Precisamos nos alegrar", continua Nietzsche, "com a nossa estupidez de vez em quando, para 
poder continuar nos alegrando com a nossa sabedoria". Com isso, Nietzsche indica que a "distância artística" também nos ensina a olhar para nós mesmos, a partir de uma distância, que não se confunde mais com o olhar sobranceiro, do alto, próprio daquele que escala montanhas para se apossar do sublime. Por fim, entretanto, em uma reviravolta completa, que afasta Nietzsche dos elementos sombrios advindos tanto de Schopenhauer quanto dos românticos, o cômico, isto é, o riso, a zombaria, a criança que pode ainda nos habitar, impõe-se para que não "percamos a liberdade de pairar acima das coisas". Ao contrário daqueles que querem pairar acima da vida, o que Nietzsche insiste aqui é que esse "pairar acima das coisas" significa não retroceder, não cair novamente nas malhas da moral e assim "poder também ficar acima da moral". Ora, o que possibilita esse ficar "acima" da moral é também a arte ou, mais propriamente falando, a künstlerische Ferne, a "distância artística". Além disso, da mesma maneira que não se pode prescindir da arte para esta tarefa de "transvaloração", não se pode prescindir igualmente do "tolo", que com seu "chapéu de bobo", dançando e flutuando, nos faz o tempo todo rir e zombar de nós mesmos, da seriedade da nossa ciência, do rigor das nossas pesquisas, da relevância social dos nossos estudos. O que a perspectiva da arte ensina à perspectiva da ciência não é apenas, tal como em $O$ nascimento da tragédia, o valor da ilusão, do erro, da mentira, mas o valor de uma "distância", que, por ser "artística", isto é, criadora, por não se orgulhar de suas conquistas vistas do alto, como se o olhar do cientista (como o do artista romântico) pudesse abarcar o "sublime", pode enfim afirmar a integridade da existência e, com isso, "pairar acima das coisas". Não como um gesto heróico, tal como o apaixonado pelo conhecimento se imagina, na medida em que não renuncia a sua paixão, mas muito mais como o gesto de um palhaço, um tolo, um Narr, como aquele que, para aprender a zombar de si mesmo precisa reconhecer-se como participante do rol dos "homens sérios e pesados". Por isso a arte, essa "boa vontade da aparência" nos é indispensável, da mesma forma que o tolo.

Esse percurso por três aforismos de A Gaia Ciência, significativos para o tema da "distância", mostrou como a crítica de Nietzsche ao romantismo (parcial, certamente injusta em alguns pontos) e também a Schopenhauer e a Wagner faz com que ele não só oponha a Distanz à Ferne, como também acaba por transformar o elemento romântico da distância, através da idéia de "distância artística". O elemento estético da "distância", que enfatiza o seu aspecto criador, vai permanecer no conceito fundamental de "pathos da distância", presente na terceira fase do pensamento de Nietzsche, a partir do Zaratustra. A "paixão pela distância", o "amor ao mais distante", que "Zaratustra" opõe ao "amor ao próximo" cristão, não responde a nenhum desejo 
nostálgico de integração, unidade ou transcendência, a nenhum afastamento radical do mundo, mas a uma consideração sobre si mesmo e sobre o mundo, que implica na permanente criação e recriação de valores. Em um mundo sem sentido, abandonado à sua própria sorte após a "morte de Deus", o "pathos da distância" diz respeito a um trabalho que visa à transformação permanente da vida em obra de arte e com isso faz da ética uma "estética da existência". 